\title{
Forma, elementos de acaso e indeterminação em música: uma introduçáo
}

\author{
Pedro Henrique Carneiro Tavares \\ Conservatório Pernambucano De Música | Orcid: 0000-0003-2225-408X
}

Resumo: $\mathrm{O}$ artigo se propóe a ser um texto introdutório acerca de conceitos relacionados à forma musical e, também, sobre o uso de elementos de acaso e indeterminação em música. Ao longo de sua exposição, transpassa brevemente por questôes relacionadas, tais como formas com caráter fechado e aberto, assim como, estratégias de invariância. Complementarmente é apresentada uma análise comparativa de três exemplos musicais, objetivando fornecer uma ilustraçáo prática dos conceitos apresentados.

Palavras-Chave: Forma Musical; Acaso e Indeterminação em Música; Estratégias de invariância.

\section{Musical form, elements of chance and indeterminacy in music: an introduction}

Abstract: The paper is intended to be an introductory text about concepts related to musical form and also about the use of elements of chance and indeterminacy in music. Throughout its exposition, there are briefly discusses related issues, such as forms with a closed and open character, as well as invariance strategies. Complementarily, a comparative analysis of three musical examples is presented, aiming to provide a practical illustration of the presented concepts.

Keywords: Musical Form; Chance and Indeterminacy in Music; Invariance strategies.

\section{El azar y la indeterminación en la música y las obras abiertas: una introducción}

Resumen: El artículo pretende ser un texto introductorio sobre conceptos relacionados con la forma musical y también sobre el uso de elementos de azar e indeterminación en la música. A lo largo de su exposición, analiza brevemente temas relacionados, como formas con un carácter cerrado y abierto, así como estrategias de invariancia. De manera complementaria, se presenta un análisis comparativo de tres ejemplos musicales, con el objetivo de brindar una ilustración práctica de los conceptos presentados.

Palabras clave: Forma musical; Azar e indeterminación en la música; Estrategias de invariancia. 


\section{Introduçáo}

A partir de observaçóes ao longo de anos lecionando no contexto de escola especializada em música, assim como tendo contatos ocasionais com estudantes e professores de outras instituiçôes de ensino, é notável que diversas linguagens musicais dos séculos XX e XXI são, ainda hoje em dia, distantes de grande parte dos estudantes de música. $\mathrm{O}$ presente artigo foi desenvolvido com a ambição de fornecer um material introdutório para diminuir parte dessa lacuna, apresentando alguns conceitos básicos sobre conceitos relacionados à forma musical e, também, sobre o uso de elementos de acaso e indeterminação em música. Temáticas relacionada são também perpassadas e brevemente apresentadas, com intuito apenas introdutório, são elas quentóes sobre formas musicais com caráter fechado e aberto, e estratégias de invariância.

O artigo apresenta também uma análise comparativa de três exemplos musicais, com objetivo de ilustração dos conceitos apresentados. Pela proposta introdutória do trabalho, julgamos enriquecedor a presença dessa exemplificação e ilustração prática dos conceitos tratados. O texto é estruturado da seguinte maneira: comentários sobre forma musical; formas "fechadas" e "abertas", intencionalmente entre aspas; acaso e indeterminação em música; estratégias de invariância; a análise comparativa dos exemplos musicais; e, por fim, algumas poucas consideraçôes finais.

\section{Forma musical}

O conceito de forma pode adotar diferentes significados, de acordo com o contexto o qual está sendo utilizado. De acordo com o Harvard Dictionary of Music (APEL, 1969. p.326-328), o termo pode se referir a duas concepçôes distintas, são elas: forma na música ou forma(s) da música. No primeiro caso o termo assume um caráter bastante geral, basicamente expressando que a música consiste de "elementos organizados de maneira ordenada, de acordo com inúmeros princípios óbvios, bem como um número ainda maior de relacionamentos sutis e ocultos" ${ }^{1}$ (APEL, 1969. p.326). No segundo caso o termo remete aos "princípios e esquemas gerais que governam a estrutura geral de uma composição" (APEL, 1969 . p.327). Schoenberg (2015) compartilha o ponto de vista sobre o termo forma poder assumir diferentes significados. Em expressóes tais como forma binária ou forma ternária o termo remete ao número de partes, ou seções, subdivisóes, da obra musical. Em casos como minueto, e outras formas de dança em geral, o termo remete às "características rítmicas, métricas e de andamento, que identificam a dança" (SCHOENBERG, 2015. p.27). No caso da expressão forma sonata, por exemplo, nos referimos a um princípio ternário com algumas características particulares, ao "tamanho das partes e a complexidade de suas inter-relaçóes" (SCHOENBERG, 2015. p.27), em outras palavras:

É essencialmente uma estrutura ternária. Suas divisóes principais são: exposição, elaboração e recapitulação. Ela difere das outras formas ternárias complexas porque a seção mediana contrastante (elaboraçáo) é quase exclusivamente

\footnotetext{
$1 \quad$ Original em inglês: "elements arranged in orderly fashion according to numerous obvious principles as well as a still greater number of subtle and hidden relationships" (APEL, 1969. p.326).

$2 \quad$ Original em inglês: "The general principles and schemes that govern the over-all structure os a composition” (APEL, 1969. p.327).
} 
devotada à elaborar a grande variedade do material temático "exposto" na primeira divisão. (SCHOENBERG, 2015. p.243).

Schoenberg afirma que, de um ponto de vista estético, o termo forma remete a maneira pela qual a obra musical é organizada, nesse sentido "ela está constituída de elementos que funcionam tal como um organismo vivo" (SCHOENBERG, 2015. p.27). Dessa maneira podemos entender que os elementos que constituem a obra musical interagem entre si, tendo funções específicas que são essenciais, em menor ou maior escala, para o funcionamento da peça como um todo. Dudeque compartilha essa interpretação ao comentar acerca de Schoenberg, segundo ele "para funcionar como um organismo os elementos constituintes da peça devem ter, cada qual, sua função específica” (DUDEQUE, 2010. p.102). A definição de Schoenberg é bastante próxima à concepção de forma(s) da música apresentada pelo Harvard Dictionary of Music, remetendo aos princípios e esquemas gerais que governam a estrutura geral de uma composição. Desta maneira entendemos que as funçôes e interconexões atribuídas aos elementos musicais têm caráter essencial na criação de uma forma musical compreensível e bem elaborada, posto de outra maneira:

Os requisitos essenciais para a criação de uma forma compreensível são a lógica e a coerência: a apresentação, o desenvolvimento e a interconexáo das idéias devem estar baseadas nas relações internas, e as ideias devem ser diferenciadas de acordo com sua importância e função. (SCHOENBERG, 2015. p.27).

A compreensão de uma forma, como colocado por Schoenberg, está associada às interconexōes entre as ideias presentes. Uma concepção a partir da corrente filosófica Gestalt apresente uma visão semelhante, segundo Rossetti (2012. p.51) trata-se de uma corrente iniciada no fim do século XIX buscando um novo princípio de descrição que fosse adequado à percepçáo. De acordo com a filosofia da Gestalt o cérebro organiza ideias a partir de operações intelectuais, partindo deste princípio:

a forma de uma obra de arte se funda no princípio de agrupamento de seus elementos, ou seja, é resultado de suas relaçóes internas. Neste contexto, uma definição de forma passaria por um grupo de elementos percebidos no seu conjunto, diferentemente de um produto de uma reuniáo do acaso. Este grupo de elementos percebidos deve constituir uma estrutura que, além de perceptível, seja inteligível (ROSSETTI, 2012. p.51).

É comum pensarmos em padróes formais tradicionais ao refletir sobre o tema. De acordo com Caplin (2010, p.21), ao pensar numa teoria da forma, normalmente propóe-se um conjunto de diversas formas específicas, tais quais como binária, ternária, sonata, rondo, dentre outras. Tais tipos formais geralmente se relacionam com gêneros e estilos de vários períodos da história da música. Tais tipos formais são compostos de unidades estruturais maiores, as seçôes da música, assim como podem possuir diversas subdivisóes estruturais menores, internas dentro de cada seção. Desta maneira:

O estudo da forma musical envolve a identificação dos sucessivos eventos musicais de uma composição. Para reconhecer esses eventos musicais, ou unidades estruturais, precisamos entender como eles são articulados no tempo. Em outras palavras, como podemos ouvir seus inícios e finais?3 (SPRING, 2013. p.19).

$3 \quad$ Original em inglês: "The study of musical form involves identifying the successive musical events of a composition. To recognize these musical events, or structural units, we need to understand how they are articulated in time. In other words, how can we hear their beginnings and endings?” (SPRING, 2013. p.19). 
Tais eventos podem ser entendidos como blocos, unidades temporais de organização, podendo ser de variadas dimensóes, Segundo Spring "Quando começamos a examinar unidades maiores, e como as unidades estáo conectadas, nossa capacidade de perceber os elementos musicais no tempo começa a se expandir, e padróes começam a emergir" ${ }^{4}$ (SPRING, 2013. p.75). Esses padróes por vezes podem assumir a organização de uma pequena forma completa, nesse caso podemos notar tais padróes formais predominando, em variadas intensidades, sobre os demais elementos musicais na organização estrutural da peça musical.

William Caplin vai mais além ao assumir que "o valor de compreender a forma em relação ao tempo musical significa que algum tipo de função formal certamente ocupará um lugar central em qualquer teoria de forma clássica"s (CAPLIN, 2010, p.40). Caplin refere-se a teoria de forma clássica, porém podemos expandir tal conceito para englobar a teoria de forma musical como um todo, de maneira mais ampla. A função formal parece indicar algum tipo de relação antecedente e consequente entre os blocos, ou estruturas musicais, entre si. Novamente a questáo temporal emerge, Dudeque compartilha tal ponto de vista ao comentar que Caplin:

enfatiza seu entendimento de um aspecto fundamental da forma musical: a associação com a "temporalidade musical". Assim ele argumenta que percebemos música como algo que possui começo, meio e fim, e que estas noçôes determinam funçôes formais específicas. (DUDEQUE, 2010, p.102-103).

O conceito, e aplicaçáo, das funçóes formais oferecem a possibilidade de entendermos a forma musical sob a ótica de que cada estrutura temporal, tendo em si uma função formal específica, está interconectada com as demais contribuindo para o funcionamento da obra como um todo. Dudeque complementa:

O entendimento de forma musical como um processo temporal é lugar comum, afinal de contas música se desenvolve no tempo. Mas o entendimento analítico de forma musical como processo engendra outras perspectivas que contemplam questóes associadas à estruturaçâo musical, a como os diversos segmentos da estrutura musical se conectam, quando apresentam uma conexão consistente entre si, muito embora em inúmeros casos estas conexóes possam não ser evidentes ou sequer existirem. (DUDEQUE, 2010, p. 111).

Muitos autores compartilham a visão da forma musical como um processo temporal, tal qual, como exemplo, Rossetti, ao afirmar que "A forma e a estrutura de uma obra musical são definidas através das periodicidades internas que são nela apresentadas" (2012, p. 122). Porém diferentes concepçóes são possíveis, abordando a questão através de outros pontos de vista, uma delas, que de certa maneira opóe-se à ênfase da continuidade temporal como princípio da forma musical, é a de Momentform (Forma Momento), proposta por Karlheinz Stockhausen. Os eventos musicais passam a ter caráter autocontido, não tendo um começo, meio e fim tal qual numa composição mais tradicional. Os momentos "se sustentariam por si só, sem necessariamente demandar um antecedente e um consequente de qualquer nível. A consistência é interna, ou seja, de organização dentro de um dado momento iso-

$4 \quad$ Original em inglês: "As we began to examine larger units, and how units are connected, our ability to perceive musical elements in time began to stretch, and patterns began to emerge" (SPRING, 2013, p. 75). 5 Original em inglês: "the value of understanding form in relation to musical time means that some account of formal functionality will certainly occupy a central place within any theory of classical form" (CAPLIN, 2010, p. 40). 
lado" (SANTOS, 2017. p.2). Ao invés da concepção tradicional de temporalidade (antes e depois), podemos afirmar que a forma momento apresenta uma "ênfase no agora e no estático" (SANTOS, 2017. p.3). Ao mesmo tempo que foca no agora e no estático, numa obra escrita na filosofia da forma momento o maior ou menor grau de mudança passa a ter um papel primordial, "Compor em função desse padrão de mudança, de uma mudança zero até um máximo definido, é o que Stockhausen entende como elemento primordial da forma momento" (SANTOS E COL. 2017. p.349).

O conceito presente na forma momento, tal como em outras abordagens realizadas nos séculos XX e XXI, está alinhado com uma nova concepção de música de maneira mais ampla. Novas concepçóes surgem notadamente a partir do início do século XX, na medida que métodos composicionais libertavam-se de padrôes do tonalismo. Incluso na busca e desenvolvimento de novos métodos, e procedimentos, não tonais:

a ideia de forma até então estabelecida foi abandonada e, por conseguinte, o modo pelo qual os compositores concebiam a ideia de tempo musical causal/ dramático, tempo este em que os materiais e temas expostos deveriam ser retomados em algum momento com a finalidade de que a obra apresentasse uma coesão do ponto de vista formal. (ROSSETTI et al. 2016. p.60)

Algumas desses novos procedimentos podem ser observados através de obras eletroacústicas. No contexto de música eletroacústica alguns locais têm grande relevância, como o Estúdio de Colônia, nele, durante a década de 1950, "estava difundida a ideia de que a composição do som estaria estritamente ligada à composição da forma, através do princípio da forma baseado na variação de pequenos elementos" (ROSSETTI et al. 2016, p. 74). Neste contexto os sons eram trabalhados, ou variados, através do manuseio de alguns de seus parâmetros, justaposição, sobreposição, etc. Na década de 1960 temos a introdução de processos algorítmicos no âmbito de composiçấo musical, que tráz consigo novas possibilidades a serem exploradas. Uma dessas possibilidades se concretiza no que Rossetti chama de forma-variante, aonde "o desenvolvimento formal de uma composição ocorre através de variantes de uma posição inicial descrita algoritmicamente" (ROSSETTI et al. 2016, p. 74), ressaltamos que a afirmaçáo trata de dados os quais referem-se aos parâmetros de um som. Em ambos os casos, a forma musical é "concebida como um processo, seja através de articulaçóes ligadas à ideia de grau de mudança, seja através de manipulaçôes algorítmicas de dados sonoros" (ROSSETTI et al. 2016, p. 75).

Um exemplo de compositor cuja abordagem formal não privilegia elementos temporais é Iannis Xenakis, segundo Rossetti o compositor trabalha a partir de uma "visão arquitetônica da forma musical, na qual o espaço é mais importante do que o tempo do ponto de vista composicional" (2012, p. 125). Porém, ao contrário do que uma visão superficial acerca do compositor pode erroneamente transmitir, o mesmo considera de extrema importância a questão temporal. Xenakis:

Chegou a afirmar, em Musique Architecture (1976), que a arte contemporânea deveria tratar de integrar as categorias perceptivas de tempo e de espaço, o continuum que nos referimos anteriormente. Para que isso acontecesse, a música, arte primordialmente temporal, deveria incorporar o espaço em seu pensamento estrutural e formal; ao mesmo tempo em que as artes preponderantemente espaciais e visuais (pintura, arquitetura, escultura) deveriam incorporar o tempo como dimensão psicológica para a apreensão de seu conteúdo, com o intuito de atingir o entendimento da totalidade de suas idéias e proposiçóes. (ROSSETTI, 2012, p.125). 
De uma maneira ou de outra, abraçando ou se propondo a negar a concepçáo de fluxo temporal (antes e depois), o tempo mostra-se fator sempre presente ao se pensar uma ideia de forma musical. Considerando o ponto de vista de forma como a maneira pela qual a música é organizada, podemos subdividi-las entre formas de caráter fechado e formas de caráter aberto.

\section{Formas "fechadas" e formas "abertas"}

É importante inicialmente esclarecer ao quê referirmo-nos através dos termos, intencionalmente deixados entre aspas, "fechadas" e "abertas". Por formas fechadas estamos remetendo a padróes diversos que moldam estruturalmente a peça musical dentro de algum modelo em particular e, mais importante, obras musicais nas quais podemos perceber uma relação exata entre aquilo que está escrito (partitura) e o resultado sonoro (execução da mesma). Ao referirmos a uma relação exata entre o que está escrito e o resultado sonoro estamos, para o propósito deste trabalho, desconsiderando pormenores de interpretação que sempre estarão presentes. Uma partitura tradicional, onde temos por escrito tudo o que deve soar (alturas), por quanto tempo (duraçóes) e de que maneira (articulaçóes, etc), é um excelente exemplo do que estamos chamando de peça em forma de caráter fechado.

Em contrapartida, por formas de caráter aberto estamos nos referindo a obras nas quais não temos um tamanho predefinido com exatidão para cada parte, bloco, ou evento sonoro, e obras nas quais não temos uma relação tão exata entre o que está escrito (partitura) e o resultado sonoro em si (performance). A questáo é expandida por Costa (2019):

Considerando que há sempre uma relação direta entre fenômeno musical (efeito) e ação performática - relação que nem sempre se dá entre aquele e a partitura, busco uma abordagem que consiga enxergar em perspectiva e de forma crítica o trinômio: estímulo - açáo - efeito. Considerando aqui que, para fazer música, é necessário um motivo e um ato e que produz-se efeitos a partir da interaçáa entre aqueles. Tal viés pode servir como incentivo a atividades interdisciplinares na área de Música pois parte de uma problematização geral do fenômeno musical, evitando considerar que aquilo que soa tenha uma origem inequívoca (uma partitura, por exemplo, ou qualquer outra determinação de cunho autoral) e concebendo a forma musical como algo necessariamente provisório e dependente de um ato de engendramento concreto. (COSTA, 2019, p. 110)

Costa nos chama a atençáo, entre outros pontos, para a possibilidade da forma musical ser concebida de forma provisória, que depende da ação performática e/ou outros fatores para se concretizar. Rossetti et al. (2016), ao comentar sobre novos rumos a respeito de forma musical, explorados a partir da música do século $X X$, afirma que em determinadas abordagens a forma é gerada juntamente ao próprio material composicional, em outras palavras "o que compreendemos agora é um processo no qual a forma é resultante externa" (ROSSETTI et al. 2016, p. 67). Dentro deste contexto:

A individuação de uma música, a constituição daquilo que compóe sua individualidade dinâmica estaria na ideia de processo de construção de formas, fundamentado nas ideias e conceitos difundidos pela mecânica quântica. Ao invés de uma forma e de um material simplesmente acoplados, e acopláveis por uma certa tradição, o que se tem é o nascimento de uma forma no momento de sua operação, a atualização da energia dentro de um sistema no momento 
de sua ocorrência, um fenômeno emergente e irreversível que não é explicável pela análise dos elementos encontrados no indivíduo após o término do processo, no qual matéria sonora e forma não são mais separáveis. (ROSSETTI et al. 2016. p.67).

A partir dos expostos por Costa e Rossetti, podemos afirmar que uma obra musical, de caráter aberto, só seria concretizada cada vez que estiver sendo executada, e a cada execução podendo assumir nova forma concreta. Costa complementa:

A partitura, num contexto como esse, de fato pode representar pouco enquanto garantia de resultados, uma vez que sua relaçáo com aquilo que soa não é imediata - ela não é solfejável. Assim, faz sentido afirmar que a referência notacional é insuficiente e que outras estratégias devem entrar em cena para que aqueles elementos morfológicos considerados essenciais não deixem de figurar enquanto parte do resultado. Ao conjunto de medidas que visam garantir resultados sonoros específicos, chamei de estratégias de invariância. (COSTA, 2011, p. 1).

Chegaremos na questão que Costa chama de estratégias de invariância, antes expomos brevemente acerca de acaso e indeterminação em música.

\section{Acaso e indeterminação em música}

Não é incomum depararmos com expressóes tais quais música aleatória, música do acaso, dentre outras, em referência a composiçōes musicais nas quais existem elementos de acaso e/ou indeterminação. A definiçăo fornecida pelo Harvard Dictionary of Music, acerca do termo "Música Aleatória", é a seguinte:

Música na qual o compositor introduz elementos de acaso ou imprevisibilidade em relação à composição ou à sua performance. Os termos aleatório, música do acaso, música de indeterminação foram aplicados a muitos trabalhos criados desde 1945 por compositores que diferem amplamente quanto a conceitos, métodos e rigor com os quais empregam procedimentos de seleção aleatória6 (APEL, 1969, p. 26-27).

Pelo exposto podemos entender que o termo aleatório refere-se a casos quando elementos de acaso ou imprevisibilidade estáo presentes, e que isso pode dar-se tanto no que concerne à composiçáo em si quanto à sua performance. Alguns questionamentos surgem a partir da citação, tais como: os termos citados - aleatório, música do acaso e música de indeterminação - são sinônimos ou se remetem a princípios e estéticas diferentes? qual a proposta por detrás dos mesmos? como esses elementos atuam?

Para expandirmos nosso conhecimento, objetivando sanar tais questóes levantadas, vamos recorrer a alguns trabalhos do professor e pesquisador Valério Fiel da Costa. $\mathrm{O}$ autor expóe acerca do termo indeterminação, quando o mesmo surge formalmente na área de música e, também, sobre seu significado. Em suas palavras:

O termo indeterminação foi usado formalmente em música, durante a segunda metade do século XX, como referência terminológica para descrever

$6 \quad$ Original em inglês: "Music in which the composer introduces elements of chance or unpredictability with regard to either the compositional or it's performance. The terms aleatoric, chance music, music of indeterminacy have been applied to many works created since 1945 by composers who differ widely as to concepts, methods, and rigor with which they employ procedures of random selection" (APEL, 1969, p. 26-27).

ICTUS Music Journal vol. 15 n.2 
e compreender a poética de alguns compositores, principalmente vinculados à chamada Escola de Nova York, grupo de compositores do qual John Cage (1912-1992) fazia parte. Segundo tal poética a busca pela cristalização de um objeto de referência morfológica, perfeitamente repetível a cada execução, cederia lugar, ou pelo menos seria considerado secundário, em relação ao seu próprio processo de configuração. Naquilo que chamou-se música indeterminada os compositores propunham, via de regra, não um texto (partitura) imediatamente materializável em uma forma sonora específica, mas algo cuja conformação final dependeria, em grande medida, de escolhas feitas a posteriori pelos intérpretes. (COSTA, 2009, p. 16)

Encontra-se diferentes definiçóes dentre os termos, por vezes usados como sinônimos, a depender da fonte consultada. Expomos a visão de Cage e Boulez sobre a questão, por sua relevância dentro do tema. Para Cage termos como acaso e indeterminaçáo "deveriam ser distinguidos conceitualmente: o primeiro significaria que uma operação de acaso (jogo de dados, consulta ao I-Ching, etc.) foi realizada para fixar uma proposta musical em uma partitura; o segundo significaria que ao intérprete é legado um nível de liberdade para remodelar o resultado sonoro" (COSTA, 2009, p. 21). Dentro dessa concepção podemos entender que o uso do acaso encontra-se no âmbito do planejamento e composição da obra musical (partitura), uma vez escrita a partitura não se diferenciaria de uma obra escrita sem elementos do acaso, ou seja, uma partitura que deve ser executada de maneira tradicional. No caso da indeterminação o compositor está legando ao intérprete liberdade de escolha que interfere diretamente na obra musical, de modo que, em si, a obra não está "fechada" numa concretização sonora única. Segundo Costa:

O conceito de indeterminação ou é inalcançável ou absolutamente abrangente.

Só é possível considerar uma peça como indeterminada, do modo proposto no enunciado cageano, ou seja, como uma obra a qual não se sabe como vai soar, desconsiderando o trabalho ativo da ação performática sobre a proposta notacional original. A performance possui uma relação estreita com a forma final e tal fato independe da satisfação do desejo do autor por invariância. (COSTA, 2019, p. 118).

Pierre Boulez adota o termo aleatório para referir-se "à tendência de se liberar o intérprete para que este intervenha criativamente sobre a obra" (COSTA, 2009, p. 22), ou seja, legar elementos de indeterminação, tal qual na visão cageana, à obra musical. Sua visão diverge da de Cage, uma vez que Cage encoraja uma maior contribuição do intérprete no resultado final, interpretação da obra musical, enquanto "Boulez não admitia que a perda do controle sobre os resultados finais de uma obra, fosse utilizando métodos randômicos a priori, fosse liberando o intérprete a posteriori, pudesse ser usado em música em proveito da arte." (COSTA, 2009, p. 22). Independente de maior ou menor abertura em relação à liberdade concedida ao intérprete, os compositores muitas vezes têm elementos que consideram essenciais para a realização de suas obras, abordaremos tal questão agora ao tratarmos de Estratégias de invariância.

\section{Estratégias de invariância}

De maneira simples, podemos estabelecer que o termo invariância remete aos elementos que não mudam a cada execução da obra musical, em outras palavras, "aquilo que, do ponto de vista do projeto composicional, deve ser repetido na obra a cada execução" 
(COSTA, 2009, p. 44). Tais elementos requerem meios, ou estratégias, através dos quais é assegurada sua presença na concretizaçáo (execução) da peça musical. Esses meios, ou estratégias, têm importância vital uma vez que é através deles que o compositor garante que o essencial, que caracteriza aquela sua obra musical, esteja presente a cada execução da peça. Costa adota o termo Estratégias de invariância para se referir a tais estratégias ou meios, em suas palavras "tudo aquilo que, a cada apresentaçáo da peça, deve, do ponto de vista do projeto composicional, levando-se em consideraçáo todas as suas etapas, repetir-se de alguma maneira, requer o que chamo de estratégia de invariância" (COSTA, 2009, p. 48). Partindo desta colocação entendemos que uma obra engloba um conjunto de elementos, podendo ser mais ou menos invariáveis, e que é possível afirmar que, em vista de sua importância na caracterizaçáo da peça musical, os eventos invariantes seriam aquilo que singulariza a obra. A importância dos elementos invariantes em obras de caráter aberto é ressaltada por Costa:

Desse modo recolocamos o problema da "obra aberta", buscando nesta não aquilo que varia ou se modifica, mas aquilo que não varia. O pressuposto é de que toda música está em constante movimento e acomodação morfológica e que o grande mistério seria justamente a sua invariância dentro de um ambiente de suposta liberdade interpretativa. (2019, p. 117).

Podemos notar que o uso criterioso de tais estratégias é de grande importância para que o compositor, ao trabalhar com uma obra aberta, assegure que sua obra sempre apresente os elementos que são considerados essenciais, segundo a visão do compositor. Podemos nos deparar com as denominaçóes estrito e flexível ao tratarmos de elementos sonoros no âmbito de obras abertas, ou música indeterminada. Os elementos essenciais para a caracterização da obra são os estritos, enquanto os flexíveis referem-se aos elementos que podem, ou devem, variar a cada apresentação da peça musical. Em outras palavras:

Seriam estritos aqueles elementos do discurso musical cujo retorno na obra, a cada performance, é dado como certo considerando o projeto composicional; seriam, portanto, elementos vinculados a alguma estratégia de invariância clara presente na obra - soam (ou espera-se que soem) da mesma forma e no mesmo ponto específico toda vez que a peça for tocada; em outras palavras, haveria, nesse caso, uma relação imediata entre a proposta de notação ou instrução e o resultado sonoro. (COSTA, 2009, p. 50)

São objetos flexíveis aqueles que têm a sua remodelagem prevista ou mesmo exigida pelo esquema composicional. Aqui o resultado sonoro depende de decisōes a posteriori que podem escapar ou não da intenção do autor. A relação entre partitura e resultado sonoro, pelo menos aparentemente, não é imediata. (COSTA, 2009, p. 50-51)

É válido destacar que pode ter toda uma gama entre as classificaçốes estrito e flexível, semelhantemente aos vários tons de cinza possíveis entre as cores preto e branco. Desta maneira os elementos, ou objetos, musicais não precisam ser totalmente estritos ou totalmente flexíveis, podendo assumir grande variedade de gradaçóes possíveis. Decorrente destas gradaçôes é possível afirmar que é possíveis particularizar as estratégias de invariância para os diversos objetos musicais, assim como afirmado por Costa: "cada objeto pode ser considerado mais ou menos essencial e motivar a elaboraçáo de sua própria estratégia de invariância" (2009, p. 65). 


\section{Análises de exemplos musicais}

Através da análise de exemplos da literatura musical são ilustradas diferentes abordagens em relação à forma musical, assim como ao uso de elementos do acaso e/ou indeterminação em música. Inicialmente é analisada a sarabanda em mi maior de autoria do compositor Johann Kuhnau, presente em sua obra Në̈er Clavier-Ubung (1689. p.16). Tal obra irá servir-nos como um exemplo de peça estruturada numa forma de caráter fechado, e, também, não contendo elementos de acaso ou indeterminação.

Tal ilustração é apresentada como ponto de partida, a partir do qual os demais exemplos podem traçar uma comparaçáo com uma peça considerada mais tradicional. Trata-se, a peça de Kuhnau, de uma composição tonal que está estruturada em duas partes, ou seja, em forma binária. Cada parte, ou seção, contém duas frases musicais. A tonalidade da obra é Mi maior, na seção " $A$ " temos a primeira frase no tom principal e a segunda no tom da dominante, a seção " $B$ " inicia na dominante mas se direciona para Fá\# menor, relativo da subdominante, e termina com uma frase no tom principal.

$\mathrm{Na}$ Figura 1 encontra-se a partitura analisada da peça, com indicaçóes quanto aos centros tonais e cadências por cima da partitura e análise dos acordes em graus romanos abaixo da partitura. O caminho Tom principal - Dominante - Retorno passando pela subdominante - Tom principal é comum, a passagem pela subdominante funciona como elemento para reestabelecer o equilíbrio no tom principal. Pode-se notar que determinadas alturas sonoras têm caráter essencial na construção da narrativa tonal, em particular a altura Lá\# que direciona para dominante (compassos 6, 7 e mais adiante no compasso 10), o retorno ao Lá bequadro (compasso 10) seguido pela altura Ré bequadro (compasso 11, tendo especial destaque como nota mais aguda da frase musical, sendo brevemente reforçada no compasso 14) que é responsável pelo reequilíbrio tonal ao compensar a ida à dominante, através dos Lá\#s anteriores, passando brevemente pela subdominante.

Interessa-nos prioritariamente observar que, na obra, temos uma forma fechada (no caso, em forma binária) e que não há elementos característicos de acaso e/ou indeterminação no âmbito de discussão do presente trabalho. Percebemos que cada parte, e cada frase dentro das partes, têm função importante na construção da narrativa, estando relacionadas umas as outras de forma a concordar com a teoria das funçóes formais propostas por Caplin, tal qual uma temporalidade tradicional (antes e depois).

O próximo exemplo analisado é o “jogo de dados”, composição interativa atribuída a Mozart. A partitura acompanha uma página de apresentação e instruções, nas quais é exposto que a mesma foi feita para que o executante possa compor sem o mínimo conhecimento de música, apenas jogando um certo número de vezes dois dados.

A "partitura" apresenta uma tabela e 176 compassos, dos quais alguns serão utilizados para construir a música. Os compassos sáo selecionados de acordo com os resultados dos números sorteados pelos dados, em concordâncias com a tabela fornecida (Mozart, 1793). A mesma, a tabela, encontra-se ilustrada na Figura 2. 
Exemplo 1: Sarabanda em Mi maior ${ }^{7}$

\section{Sarabande}

Johann Kuhnau

$\mathbf{A}$

$\mathrm{E}$

CAI

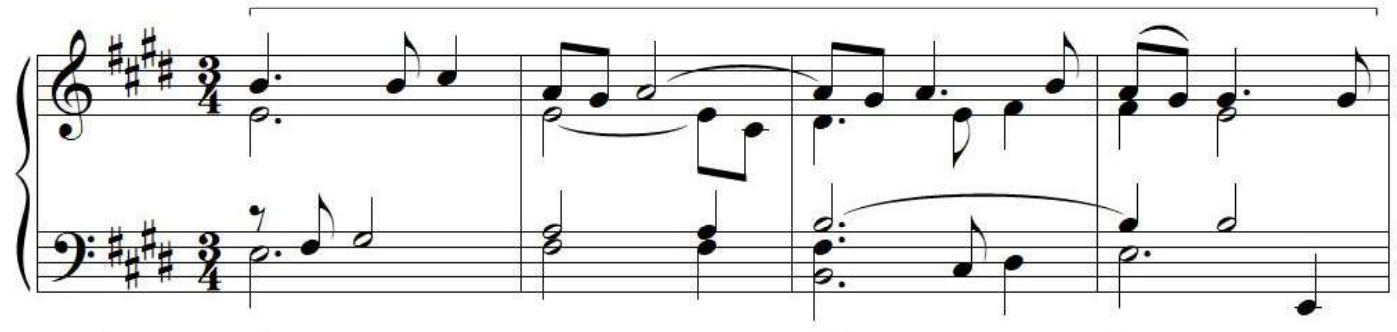

E: $\quad I$

ii7

V7

CAI

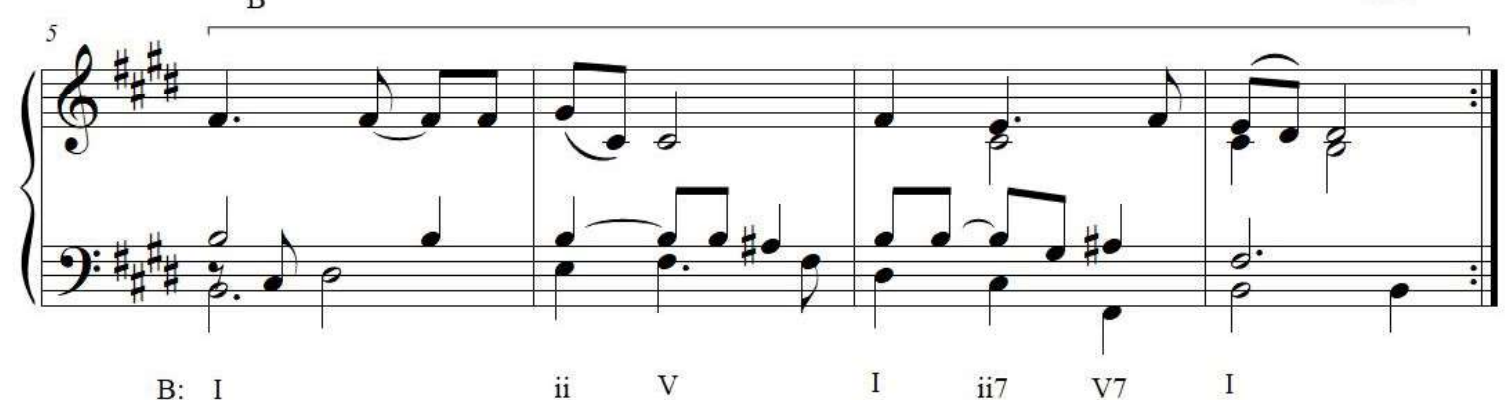

B: I

$\mathrm{F} \# \mathrm{~m}$

CAI

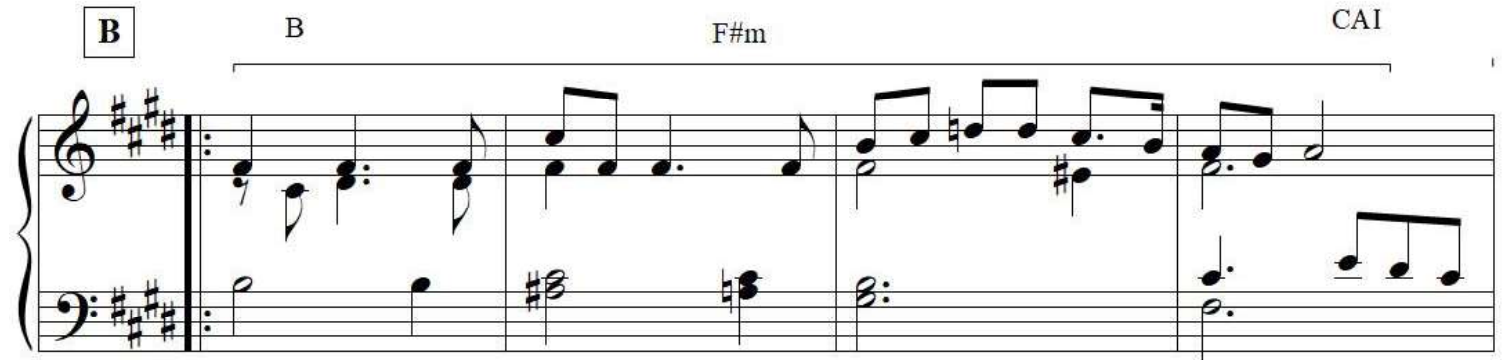

V6 F\#m: i6 viio7

CAP

$\mathrm{E}$

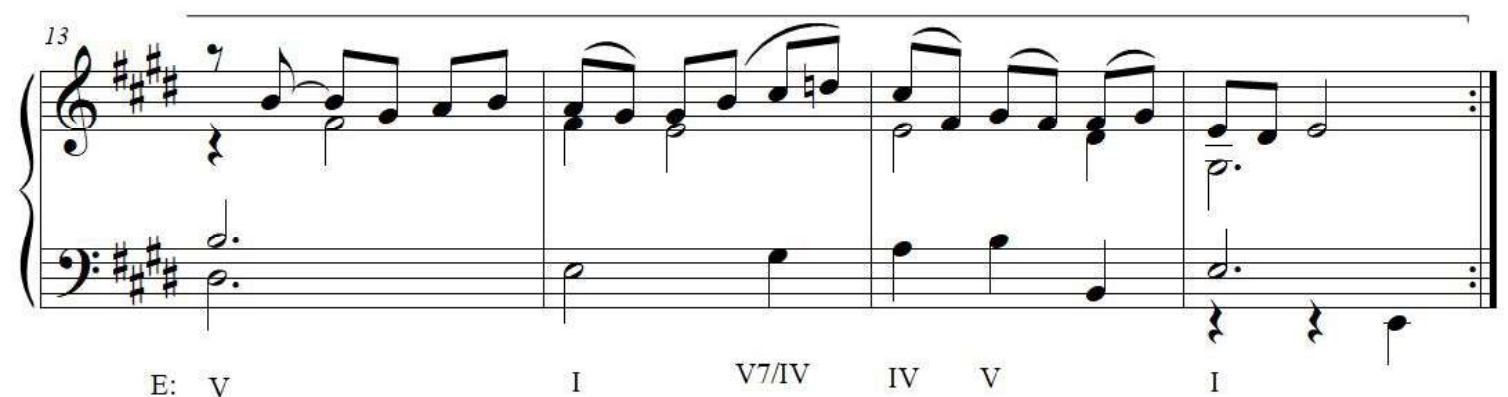

Fonte: Editoraçáo e análise própria, a partir da partitura original presente em Neüer Clavier-Ubung $(1689)^{8}$.

7 Link para escutar no Youtube: https://www.youtube.com/watch?v=oOCMCYI0gFI. (Acesso em: $16 / 07 / 2020)$

8 Disponível em: http://conquest.imslp.info/files/imglnks/usimg/2/23/IMSLP273679-PMLP444279-Ne\%C3\%Bcer Clavier-Ubung, Erster Theil.pdf. Acesso em: 16/07/2020.

ICTUS Music Journal vol. 15 n.2 
Figura 2: Tabela do jogo de dados de Mozart

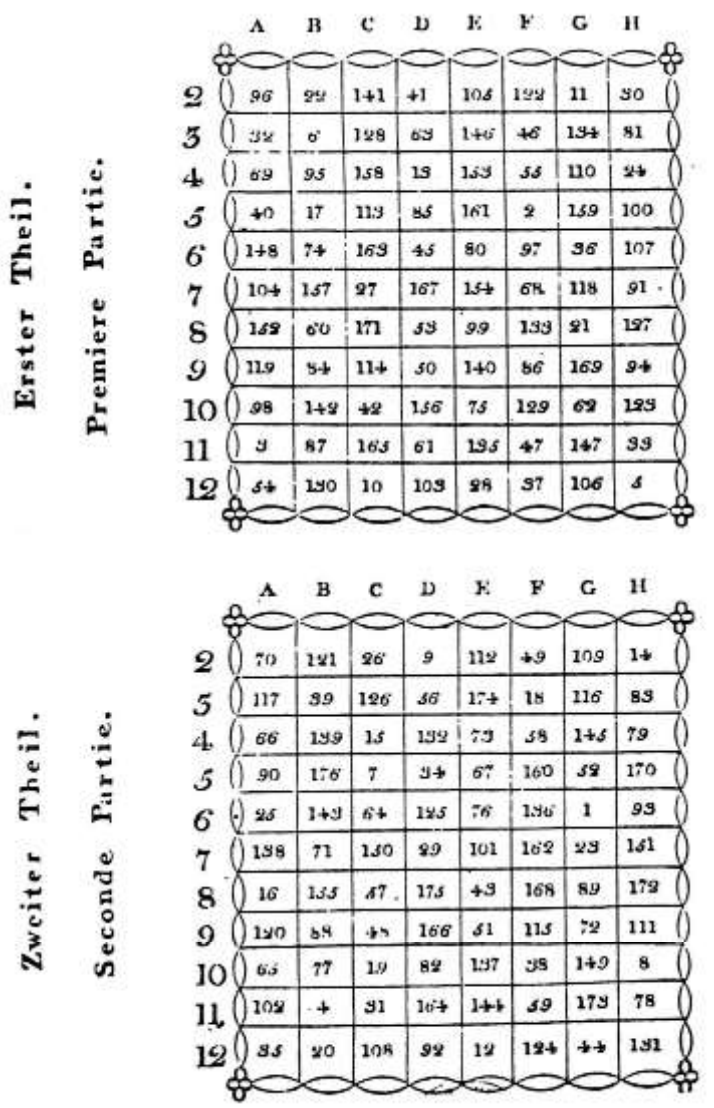

Fonte: Ilustração extraída de Musikalisches Würfelspiel (Mozart, 1793) ${ }^{9}$

A tabela deve ser aplicada na construção de uma peça estruturada em duas partes, cada parte contendo oito compassos, representados na tabela pelas colunas com letras de "A" a "H". As linhas, com números de 2 a 12, representam as possibilidades de soma dos dados, 2 sendo o menor possível, soma de 1 e 1, e 12 o maior, soma de 6 e 6 . O executante deve atirar dois dados, de seis lados, e somar os resultados, então utilizar o número obtido pela soma para determinar qual compasso, dos 176 apresentados, deve ser escrito naquele local específico, compasso da composição. Por exemplo, vamos imaginar que dois dados são arremessados e apresentam resultados 4 e 3, somamos os números e obtemos o total de 7 , em seguida vamos na tabela de Mozart e vemos a coluna " $A$ " da primeira parte, que deve ser o primeiro compasso da nossa peça. O resultado indicado na coluna "A", da primeira parte, na linha 7 , é 104 . O mesmo procedimento deve ser repetido até a coluna " $H$ " da segunda parte, completando os 16 compassos da peça musical.

Vale salientar que o número de possibilidades da composição completa é imenso, temos para cada compasso 11 diferentes resultados possíveis, de 2 a 12, e 16 compassos ao total na peça musical. A título de ilustração podemos notar que temos 11 possibilidades distintas para apenas um compasso, para dois compassos temos onze vezes onze possibilidades de combinaçóes, 112, resultando em 121 diferentes possíveis combinaçóes, para três compassos temos 113, resultando 1331 possíveis combinaçóes, etc. Seguindo o mesmo raciocínio até o ponto aonde temos a peça musical completa, com seus dezesseis compassos, temos 1116 possíveis diferentes combinaçóes, e, consequentemente, resultados finais.

9 Disponível em: https://imslp.org/wiki/Musikalisches W\%C3\%Bcrfelspiel, K.516f (Mozart, Wolfgang Amadeus). Acesso em: 28/06/2020. 
Considerando o raciocínio exposto, as 1116 possíveis combinaçóes, ou, escrito de outra maneira, as 45.949.729.863.572.161, aproximadamente 46 quadrilhóes, possibilidades de combinaçóes de resultados diferentes, praticamente garantem que a cada vez que se "joguem" os dados para montar uma versão da composição, o resultado seja novo em cada uma dessas vezes. Para fins de demonstração, está ilustrada na Figura 3 uma realização obtida através do jogo de dados.

Figura 3: Uma realização do jogo de dados ${ }^{10}$
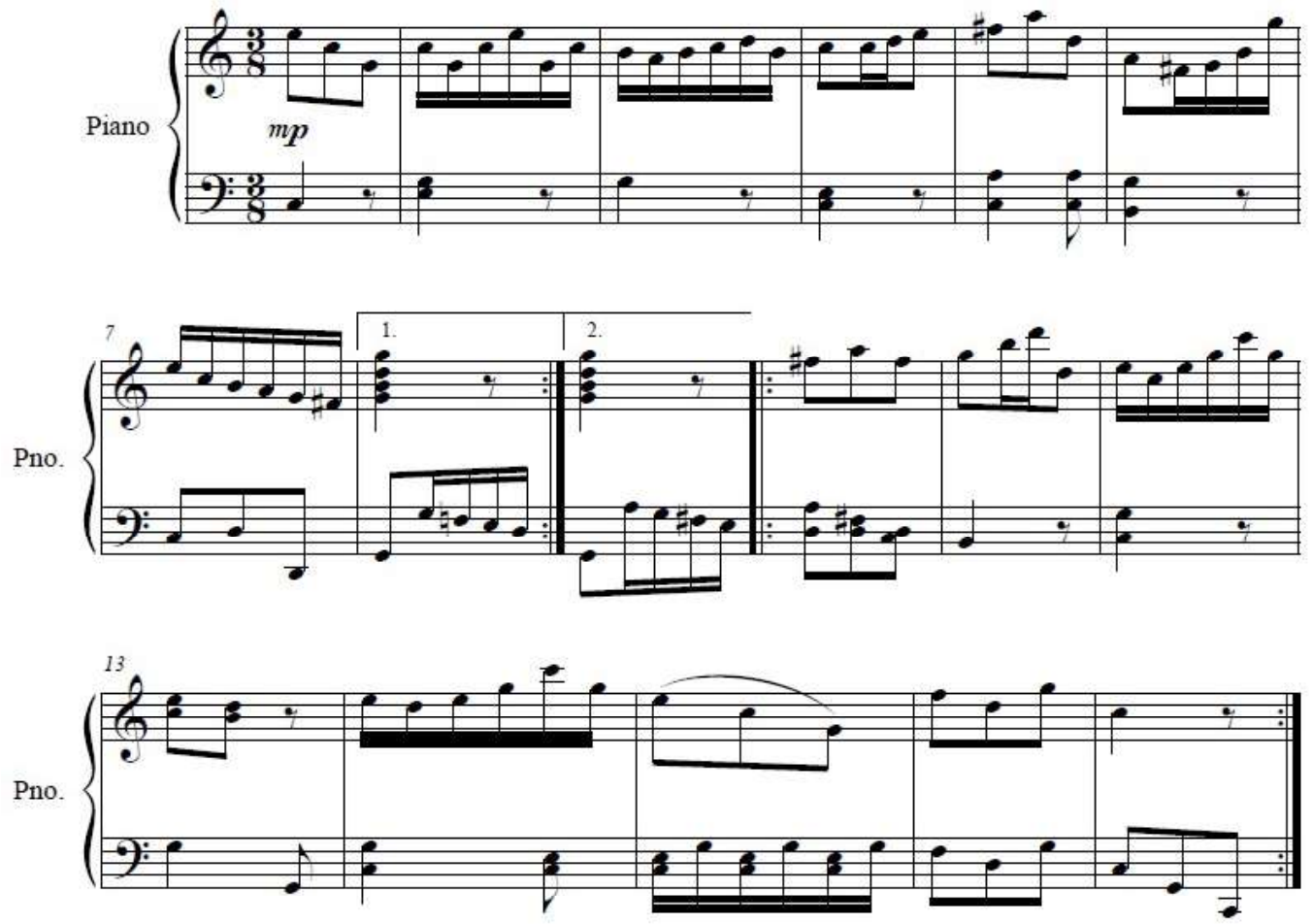

Fonte: Elaboração própria.

A maneira pela qual Mozart tem controle do resultado final, ou, colocado de outra maneira, sua estratégia de invariância, parece ser através do controle da harmônia. Trata-se de uma composição tonal, em Dó maior.

Todos os compassos listados como possibilidade para iniciar - compasso 1 - e finalizar - compasso 16 - a peça são o acorde da tônica no estado fundamental, alguns deles contendo notas melódicas enquanto outros apenas as notas do acorde. Percebemos também que, no caso das opçôes possíveis para o final da peça, há repetição literal de alguns compassos, mesmo que com numeração diferente. Em outras palavras, alguns compassos com numeração diferente são, na prática, exatamente os mesmos. Nas opçóes para o compasso 8 , por exemplo, percebemos também a repetição de opções com numeraçóes diferentes. Neste caso - compasso 8 - Mozart escreve duas linhas sobrepostas com números 1 e 2 , escritos na nossa realização como casa 1 e casa 2 . Na casa 1 a harmônia é V7(G7), utilizando Fá bequadro para retornar ao $\mathrm{I}(\mathrm{C})$ do compasso 1 . Na segunda casa é utilizada a nota Fá sustenido, tonicalizando a regiáo de Sol maior (tom da dominante) para seguir à segunda parte da música. Neste exemplo podemos classificar a forma como "fechada", visto que, apesar de adotar elementos interativos, assim como certo grau de indeterminaçáo, tais 10 Link para escutar no Youtube: https://www.youtube.com/watch?v=lp-4J9Oaiwo (Acesso em: $28 / 06 / 2020)$ 
elementos não interferem na forma da composição em si - Binária, cada parte contendo oito compassos e tendo dupla exposição (ritornelos) - e sim no conteúdo exposto em cada compasso dentro desta forma.

O próximo exemplo ao qual recorremos é a composição Alcázar III, com autoria de Peter Tod Lewis. Lewis (1972) inicia orientando em relação à instrumentação, pede um mínimo de quatro instrumentos de altura definida, e máximo de orquestra completa, ressalta que instrumentos transpositores podem tocar como "escrito". Suas instruçôes iniciam com uma citação de Alice no País das Maravilhas, que diz "Comece no início, vá para o final, e então pare", em seguida pede que o(s) músico(s) não vire $(\mathrm{m})$ a página até o regente dar o sinal, que também significa o início da peça. Segue informando que a partitura é um labirinto, cuja entrada está na parte inferior direita. Os músicos devem ir percorrendo o labirinto e tocando as alturas sonoras "encontradas" pelo caminho, em qualquer oitava. As alturas são escritas através de cifras. Cada executante pode ir explorando os caminhos em sua própria velocidade, e pelas rotas que escolher, de maneira que cada execução da peça tende a ser única. Da partitura de Lewis podemos reproduzir uma captura de tela, feita de vídeo de acesso público postado no Youtube, com objetivo de ilustrar um recorte de sua partitura gráfica em formato de labirinto. (Figura 4)

Alguns elementos, tal como inseridos na partitura e/ou descritos nas instruçóes pelo compositor, apresentam-se como elementos fixos, ou estritos se recorremos à denominaçóes expostas anteriormente ao tratarmos de música indeterminada. As sequências de alturas ao longo dos caminhos, a dinâmica pedida, "tão suave quanto possível", e a sustentação da nota final (Fá\#), com diminuendo, por volta de 5 segundos, são exemplos de tais elementos. Podemos considerar tais elementos como estratégias de invariâncias empregadas por Lewis.

De acordo com conceitos expostos, é possível classificar a peça, Alcázar III, como tendo uma forma "aberta", visto que não existe um padrão formal bem estabelecido. Aqui a forma acaba resultando da interação entre diversas interpretaçóes possíveis dos músicos, tendo forte tendência de ser nova a cada execução.

\section{Consideraçôes finais}

O presente artigo buscou introduzir conceitos acerca de forma musical e do uso de elementos de acaso e indeterminaçáo em música, passando também por questôes referentes a formas "fechadas" e "abertas" e, também, das estratégias de invariância. Complementarmente foram trazidas análises musicais almejando a ilustração prática dos conceitos trazidos pelo texto.

Tal trabalho, almejando ter caráter introdutório, foi elaborado no intuito de, através dos conteúdos e casos particulares citados, preencher um pouco da lacuna percebida e citada na introdução deste presente trabalho. A lacuna refere-se ao pouco conhecimento, ou distanciamento, de parte das diversas linguagens musicais dos séculos XX e XXI por parcela significativa dos estudantes de música no contexto de escolas especializadas, assim como, também, estudantes de música no geral. É notório que o exposto através deste artigo é apenas uma pequena parcela de um vasto, e diverso, campo que sáo as linguagens musicais dos séculos XX e XXI. Considerando a afirmação anterior, é expectativa deste artigo incentivar o interesse, e pesquisa, por outros trabalhos que contribuam com o enriquecimento do conhecimento sobre esse campo tấo vasto e diverso. 
Figura 4: Um recorte da partitura de Lewis.

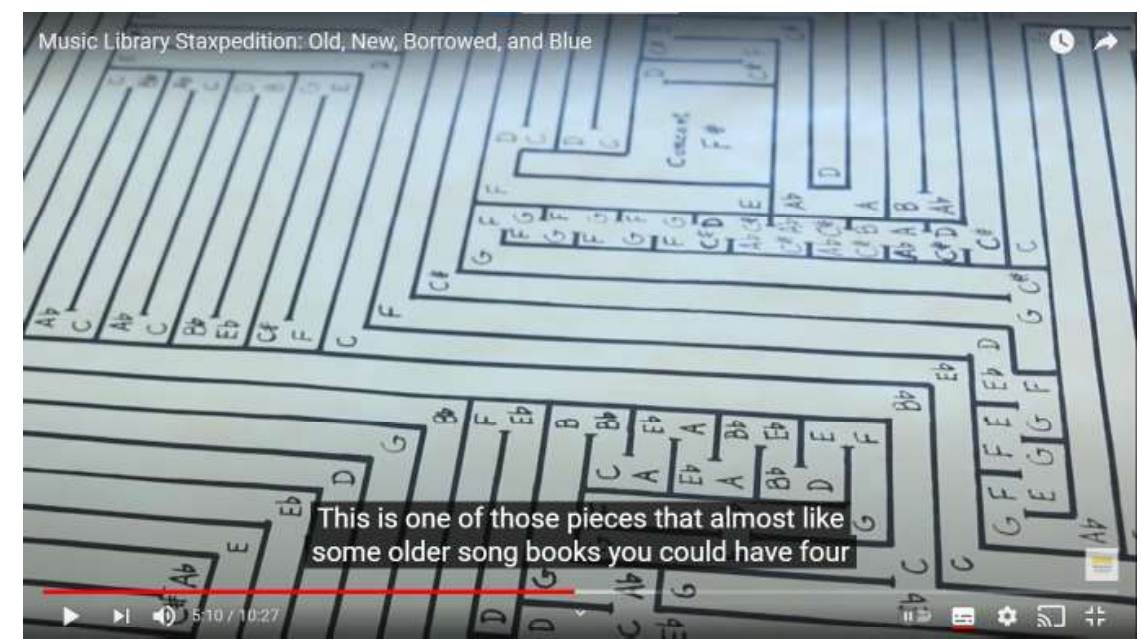

Fonte: Captura de tela (05:10) de vídeo público no Youtube ${ }^{11}$.

\section{Referências}

APEL, Willi. Harvard Dictionary of Music. 2.ed. Belknap Press of Harvard University Press. Cambridge, Massachusetts. 1969.

CAPLIN. William E. What are formal functions?: Musical form, forms \& formenlehre. Editado por Pieter Bergé. 2.ed. Leuven University Press. 2010. p.21-40.

COSTA, Valério Fiel da. Analise morfológica a partir da performance no projeto artesanato furioso. A Experiência Musical: Perspectivas teóricas. Salvador: TeMA, 2019. P.110-121.

Disponível em: https://www.academia.edu/40424822/COSTA analise morfol\%C3\%B3 gica a partir da performance no projeto artesanato furioso. Acesso em: 08/07/2020.

COSTA, Valério Fiel da. Consideraçóes Sobre a Forma em peças de Caráter Aberto de Cage e Stockhausen. XXI Congresso da Associação Nacional de Pesquisa e PósGraduação em Música. Uberlândia, 2011.

Disponível em: https://www.academia.edu/36267529/Considera\%C3\%A7\%C3\%B5es Sobre a Forma em pe\%C3\%A7as de Car\%C3\%A1ter Aberto de Cage e Stockhausen. Acesso em: 23/06/2020.

COSTA, Valério Fiel da. Da indeterminaçáo à invariância: Consideraçôes sobre morfologia musical a partir de peças de caráter aberto. Tese (doutorado em música). Universidade Estadual de Campinas. Campinas, 2009. Disponível em: http:// repositorio.unicamp.br/jspui/handle/REPOSIP/284681. Acesso em: 08/07/2020.

11 Music Library Staxpedition: Old, New, Borrowed, and Blue. Captura em 05:10. Disponível em: https://www.youtube.com/watch?v=buVmOkoAokE. Acesso em: 08/10/2020. 
DUDEQUE, Norton. Forma musical como processo. I Simpósio Brasileiro de Pós-Graduandos em Música - XV Colóquio do Programa de Pós-Graduaçáo em Música da UNIRIO. Rio de Janeiro, 2010. p.99-112. Disponível em: https://www.academia. edu/367987/FORMA MUSICAL COMO PROCESSO . Acesso em: 05/07/2020.

KUHNAU, J. Neüer Clavier-Ubung. 1689. 1 partitura. Disponível em: http://conquest. imslp.info/files/imglnks/usimg/2/23/IMSLP273679-PMLP444279-Ne\%C3\%Bcer Clavier-Ubung, Erster Theil.pdf. Acesso em: 16/07/2020.

LEWIS, Peter Tod. Alcázar III. 1972. 1 partitura.

MOZART, Wolfgang Amadeus. Musikalisches Würfelspiel. Bonn: N. Simrock, n.d., 1793. 1 partitura. Disponível em: https://imslp.org/wiki/Musikalisches W\%C3\%Bcrfelspiel, K.516f (Mozart, Wolfgang Amadeus). Acesso em: 28/06/2020.

Music Library Staxpedition: Old, New, Borrowed, and Blue. In: Special Collections \& Archives, UIowa Libraries (Canal do Youtube). Disponível em: https://www.youtube.com/watch?v=buVmOkoAokE. Acesso em: 08/10/2020.

ROSSETTI, Danilo; FERRAZ, Silvio. Forma musical como um processo: do isomorfismo ao heteromorfismo. Opus, v.22, n.1, p.59-96, 2016. Disponível em: https://www. academia.edu/26601853/Forma como processo do isomorfismo ao heteromorfismo. Acesso em: 09/09/2020.

ROSSETTI, Danilo. O tempo e sua reflexão a partir da obra de Iannis Xenakis. Dissertação (Mestrado em Música) - Universidade Estadual Paulista. São Paulo, 2012. Disponível em: https://www.academia.edu/14541006/O tempo e sua reflex\%C3\%A3o a partir da obra de Iannis Xenakis. Acesso em: 10/09/2020.

SANTOS, Jorge L. Forma momento e descontinuidade temporal em Chronochromie de Olivier Messiaen. XXVII Congresso da Associação Nacional de Pesquisa e Pós-Graduação em Música. Campinas, 2017. Disponível em: https://www.academia.edu/34438342/ Forma momento e descontinuidade temporal em Chronochromie de Olivier Messiaen XXVII Congresso da Associa\%C3\%A7\%C3\%A3o Nacional de Pesquisa e P\%C3\%B3s-Gradua\%C3\%A7\%C3\%A3o em M\%C3\%Basica 2017. Acesso em: 15/07/2020.

SANTOS, Jorge L.; FERRAZ, Silvio. Três experiências da Forma Momento: um modelo formal do agora. $4^{\circ}$ encontro internacional de teoria e análise musical. Sáo Paulo, 2017. p.347-360. Disponível em: https://www.academia.edu/33440246/Tr\%C3\%Aas experi\%C3\%Aancias da Forma Momento um modelo formal do agora. Acesso em: 15/07/2020.

SCHOENBERG, Arnold. Fundamentos da composiçáo musical. Tradução de Eduardo Seincman - 3.ed. 3. reimpr. - São Paulo: Editora da Universidade de São Paulo, 2015.

SPRING, Glenn; HUTCHESON, Jere. Musical form and analysis: time, pattern, proportion. Waveland Press, Inc. 2013. 